\title{
Dexamathasone added to levobupivacaine improves postoperative analgesia in ultrasound guided interscalene brachial plexus blockade for arthroscopic shoulder surgery
}

\author{
Youn Jin Kim, Guie Yong Lee, Dong Yeon Kim, Chi Hyo Kim, Hee-Jung Baik, and Seok Heo \\ Department of Anesthesiology and Pain Medicine, School of Medicine, Ewha Womans University, Seoul, Korea
}

Background: The purpose of this study was to evaluate the effect of the addition of $5 \mathrm{mg}$ dexamethasone to $10 \mathrm{ml}$ of $0.5 \%$ levobupivacaine on postoperative analgesic effects of ultrasound guided-interscalene brachial plexus block (ISBPB) in arthroscopic shoulder surgery under general anesthesia.

Methods: In 60 patients scheduled for arthroscopic shoulder surgery that underwent general anesthesia, ISBPB was preoperatively performed with $10 \mathrm{ml}$ of $0.5 \%$ levobupivacaine under the guidance of ultrasound and a nerve stimulator. Patients were randomly allocated to receive the same volume of normal saline (Group I), $5 \mathrm{mg}$ of dexamethasone (Group II), or $1: 400,000$ epinephrine (Group III) as an adjuvant to the mixture. A blind observer recorded total analgesic consumption, sleep quality, complication, and patient satisfaction using a verbal numerical rating scale (VNRS) at $0,1,6,12,24,48 \mathrm{~h}$ after the operation.

Results: All patients had successful ISBPB and excellent analgesic effects less than VNRS 4 up to discharge time. VNRS in Group II at $12 \mathrm{~h}$ and $48 \mathrm{~h}$ was statistically much lower than in Group I and III. There were no differences in total analgesic consumption, sleep quality, complications, and patient satisfaction.

Conclusions: We conclude that the addition of $5 \mathrm{mg}$ of dexamethasone to $10 \mathrm{ml}$ of $0.5 \%$ levobupivacaine in ISBPB showed improvement of postoperative analgesia for arthroscopic shoulder operation without any specific complications. (Korean J Anesthesiol 2012; 62: 130-134)

Key Words: Analgesia, Brachial plexus blocks, Dexamethasone, Levobupivacaine, Ultrasound.

Received: March 16, 2011. Revised: 1st, July 4, 2011; 2nd, September 14, 2011. Accepted: September 15, 2011.

Corresponding author: Youn Jin Kim, M.D., Department of Anesthesiology and Pain Medicine, School of Medicine, Ewha Womans University, 911-1, Mok-dong, Yangcheon-gu, Seoul 158-710, Korea. Tel: 82-2-2650-5285, Fax: 82-2-2655-2924, E-mail: ankyj@ewha.ac.kr

(c) This is an open-access article distributed under the terms of the Creative Commons Attribution Non-Commercial License (http:// creativecommons.org/licenses/by-nc/3.0/), which permits unrestricted non-commercial use, distribution, and reproduction in any medium, provided the original work is properly cited. 


\section{Introduction}

Interscalene brachial plexus block (ISBPB) is one of the most commonly used and most clinically applicable nerve block techniques, particularly for shoulder joint surgery and postsurgery pain control. In addition to the common approaches of the classic technique (Winnie) [1], posterior approach (Pippa) [2], and the modified lateral technique (Borgeat) [3], recently, low volume ISBPB has been developed to be easily conducted in real-time under ultrasonic guidance.

It has been reported that ISBPB in arthroscopic shoulder surgery with low dosages of bupivacaine and ropivacaine showed significant postoperative analgesic effects, and using levobupivacaine in ISBPB has been reported to have a longer duration of sensory block than ropivacaine $[4,5]$. Kim et al. [6] reported that the single-shot blockade effect of ultrasoundguided ISBPB using $10 \mathrm{ml}$ levobupivacaine continued for 8 hours after the surgery. Placement of the catheter for continuous ISBPB can be considered for prolonged pain control after surgery, but it may be a challenging technique to apply to all patients who need arthroscopic shoulder surgery due to it failing to gain popularity from patients and clinicians because of technical proficiency $[1,7,8]$.

For single-shot techniques, various local anesthetic (LA) mixtures can be used to prolong local anesthesia duration, and epinephrine, bicarbonate, neostigmine, opioids, and clonidine are frequently used for this purpose. As well as delaying absorption by vasoconstriction, epinephrine is the agent added most often to the LA, which is known to have $\alpha-2$ adrenergic mechanism that works directly on the spinal cord to suppress pain, but caution is required when adding epinephrine to patients with risk factors such as hypertension and ischemic heart problems $[9,10]$. Addition of long-acting glucocorticoid steroids characterized to induce a degree of vasoconstrictor and anti-inflammatory effects are used to treat chronic pain syndrome and have been tested in some animal and human studies, which recently reported that adding dexamethasone microspheres in the LAs prolonged anesthesia duration, but these results also stated that dexamethasone affected the central nerves when added to spinal anesthesia using bupivacaine and the effect of systemically injected corticosteroid [11-17]. However, research concerning the effect on local anesthesia of corticosteroids added for peripheral nerve block is still very limited.

Therefore, we conducted ultrasound guided-ISBPB on patients undergoing arthroscopic shoulder surgery using $10 \mathrm{ml}$ $0.5 \%$ levobupivacaine with added $5 \mathrm{mg}$ dexamethasone and investigated postoperative analgesic effects.

\section{Materials and Methods}

The study was approved by the Hospitals Ethics Committee and was conducted on 60 American Society of Anesthesiologists 1, 2 patients over the age of 18 who were undergoing arthroscopic shoulder surgery. The purposes of this study and the risks and complications that may come from the procedure were explained to subjects and their consent was obtained. Patients unable to cooperate, diabetics, expectant mothers, patients with coagulation difficulties, those sensitive to local anesthesia, patients with severe chronic pulmonary disease, neurological deficiencies at the site of operation or neuropathy, infections at the site of block, drug or alcohol abusers, and those with a medical history of chronic pain were excluded from the study.

Patients were randomly allocated into three groups and ISBPB was preoperatively performed under the guidance of ultrasound and nerve stimulator using $10 \mathrm{ml}$ of $0.5 \%$ levobupivacaine (Chirocaine ${ }^{\circledR}$, Abbott Scandinavia AB, Solna, Sweden) with identical dosages of different additives. Group I ( $\mathrm{n}=20$ ) was administered with $1 \mathrm{ml}$ of normal saline solution, $5 \mathrm{mg}$ of dexamethasone (Dexamethasone disodium phosphate injection $^{\circledR}$, Yuhan Pharm, Seoul, Korea) was administered to Group II ( $\mathrm{n}=20)$, and $1: 400,000$ epinephrine was administered to Group III $(\mathrm{n}=20)$.

Noninvasive monitoring of blood pressure, pulse oxymetry and electrocardiograms were attached to all patients immediately after arrival into the operating room, and their initial vital signs were measured. ISBPB was conducted after IV injection of midazolam $1-3 \mathrm{mg}$ and fentanyl $25-50 \mu \mathrm{g}$. The patient was laid in a supine position with the head turned away from the side to be blocked. Betadin was applied to the skin, and the round to oval-shaped honeycomb appearance of hypoechoic nerve roots in short-axis view located between the anterior scalene muscle (ASM) and middle scalene muscle (MSM) were identified using a 5-12 MHz linear probe of ultrasound (SonoSite M-TurboTM, SonoSite, Bothell, USA). The point where the $\mathrm{C} 5 / 6 / 7$ roots were most visible was selected. The linear probe was draped with disinfected wrap and gel, and a $22 \mathrm{G} 50 \mathrm{~mm}$ length needle (Stimuplex ${ }^{\circledR}$, B. Braun Melsungen, Melsungen, Germany) connected to a nerve stimulator (Stimulplex DIG ${ }^{\circledR}$, B. Braun, Melsungen, Germany) was used to approach via the in-plane method. The needle tip was positioned between the C5/6 roots or superior trunk within the sheath, and LAs for each group were slowly administered after any twitch confirmation from the deltoid, pectoralis major, triceps, or biceps through $1 \mathrm{~Hz}$ and less than $0.5 \mathrm{~mA}$ of electrical stimulation, and when blood was not absorbed through suction (to rule out injection into the bloodstream). Medication diffusion was observed with ultrasound, and needle position was adjusted so all nerve roots within the sheath could be surrounded. All ISBPB procedures 
were conducted by one anesthesiologist, and all surgeries were performed by one surgeon.

After the procedure, general anesthesia induction was done immediately. A bispectral index was mounted on all three groups and after IV injecting glycopyrrolate $0.2 \mathrm{mg}$, pentothal sodium ( $4 \mathrm{mg} / \mathrm{kg})$, fentanyl $(1-2 \mu \mathrm{g} / \mathrm{kg})$ and rocuronium $(0.6 \mathrm{mg} / \mathrm{kg})$ were used to intubate. General anesthesia was maintained using $50 \%$ oxygen-nitrous oxide mixture and sevoflurane( $0.5-2.0 \mathrm{vol} \%)$ to control BIS value to $40-60$ and systolic blood pressure to $90-100 \mathrm{mmHg}$. Pyridostigmine and glycopyrrolate were used for reversal of the residual muscle relaxation.

A doctor blinded to the study groups visited the patients and used the verbal numerical rating scale (VNRS: $0=$ no pain, $10=$ most severe pain imaginable) to evaluate and record pain starting with immediately after recovery room arrival as 0 and $1,6,12,24$, and $48 \mathrm{~h}$ later. When VNRS was more than 4 and the patient requested analgesic, ketorolac was IV injected or opioid IM injected and recorded, and patients were evaluated whether they exhibited complications such as neurological disabilities, nausea, vomiting, or respiratory difficulties.

SPSS (version 17.0, Chicago, IL, USA) was used for statistical analysis and continuous variables were noted as mean \pm standard deviation, VNRS as mean \pm standard error and

Table 1. Demographic and Clinical Data for Ultrasound Guided Interscalene Brachial Plexus Blockade in Arthroscopic Shoulder Surgery

\begin{tabular}{lccc}
\hline & $\begin{array}{c}\text { Group I } \\
(\mathrm{n}=20)\end{array}$ & $\begin{array}{c}\text { Group II } \\
(\mathrm{n}=20)\end{array}$ & $\begin{array}{c}\text { Group III } \\
(\mathrm{n}=20)\end{array}$ \\
\hline Age (yr) & $50.8 \pm 14.6$ & $47.0 \pm 15.5$ & $44.2 \pm 16.7$ \\
Height (cm) & $164.9 \pm 8.9$ & $162.7 \pm 9.2$ & $167.9 \pm 8.7$ \\
Weight (kg) & $68.9 \pm 11.2$ & $68.3 \pm 11.2$ & $71.8 \pm 13.3$ \\
Sex (M/F) & $15 / 5$ & $12 / 8$ & $13 / 7$ \\
ASA (I/II) & $9 / 11$ & $6 / 14$ & $10 / 10$ \\
Duration of & $84.3 \pm 23.7$ & $76.5 \pm 21.1$ & $71.8 \pm 13.3$ \\
operation (min) & & & \\
Duration of & $143.8 \pm 29.4$ & $141.4 \pm 26.7$ & $150.5 \pm 40.6$ \\
anesthesia (min) & & & \\
Operative type & & 14 & 10 \\
Rotator cuff repair & 13 & 2 & 1 \\
ASD & 1 & 3 & 2 \\
SLAP repair & 4 & 1 & 2 \\
Bankart repair & 1 & 0 & \\
Capsular shifting & 1 & & \\
\hline
\end{tabular}

Values are expressed as mean \pm SD or numbers. Group I: $1 \mathrm{ml}$ normal saline as an adjuvant to $10 \mathrm{ml}$ of $0.5 \%$ levobupivacaine for interscalene brachial plexus blockade, Group II: $1 \mathrm{ml}$ of $5 \mathrm{mg}$ dexamethasone as an adjuvant to $10 \mathrm{ml}$ of $0.5 \%$ levobupivacaine for interscalene brachial plexus blockade, Group III: $1: 400,000$ epinephrine as an adjuvant to $10 \mathrm{ml}$ of $0.5 \%$ levobupivacaine for interscalene brachial plexus blockade. ASD: arthroscopic subacromialdecompression, SLAP: superior labrum anterior posterior. There were no significant differences among the groups. analyzed using ANOVA. Categorical variables were noted in number of patients (\%) and analyzed using chi-squared and Fisher's exact test. A P value of $<0.05$ was considered statistically significant.

\section{Results}

There were no significant differences in age, height, weight, sex, ASA PS, time taken for surgery and anesthesia, and type of surgery among the three groups (Table 1). Patients from all three groups showed excellent analgesic effects with VNRS lower than 1 point up to $6 \mathrm{~h}$ after surgery.

VNRS measured at 12, 24 and $48 \mathrm{~h}$ after surgery showed that of Group II scored 0.3, 2.4, 1.1 points, which was notably lower compared to Group I (2.6, 3.7, 2.9 points) and Group III (3, 3.5, 2.6 points) (Fig. 1). However, all three groups exhibited excellent analgesic effect with lower than 4 points in VNRS measured up to 48 hours after surgery, and the amount of additional analgesic used was not significantly different. All nerve blocks were recovered within 24 hours, and all patients were satisfied with no complaints of complications or side effects.

\section{Discussion}

This study conducted ultrasound-guided single-shot ISBPB on patients undergoing arthroscopic shoulder surgery using $0.5 \%$ levobupuvacaine $10 \mathrm{ml}$. This procedure showed excellent pain control of less than 1 point VNRS up to 6 hours postsurgery. When $5 \mathrm{mg}$ dexamethasone was added to the ISBPB

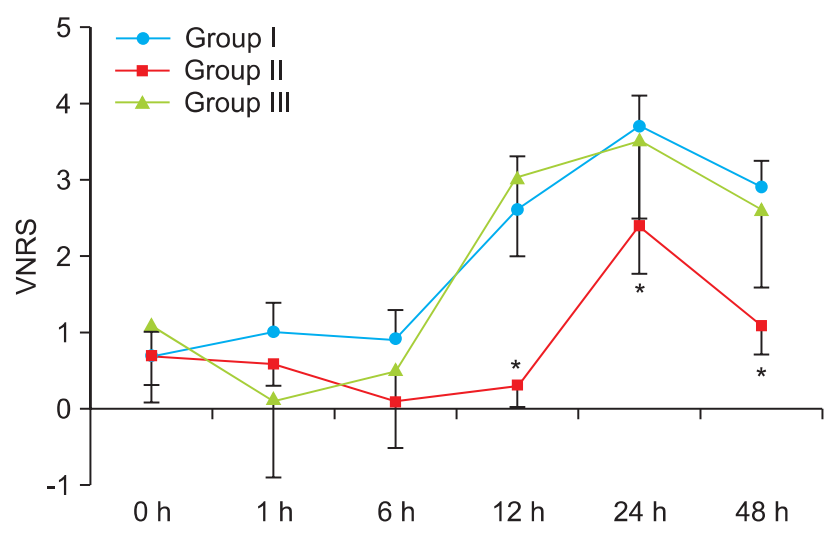

Fig. 1. Verbal numerical rating scale (VNRS) according to the time interval after arthroscopic shoulder surgery. Values are expressed as mean $\pm \mathrm{SD}$. ${ }^{*} \mathrm{P}<0.05$ compared with Group I. Group I: $1 \mathrm{ml}$ normal saline as an adjuvant to $10 \mathrm{ml}$ of $0.5 \%$ levobupivacaine for interscalene brachial plexus blockade, Group II: $1 \mathrm{ml}$ of $5 \mathrm{mg}$ dexamethasone as an adjuvant to $10 \mathrm{ml}$ of $0.5 \%$ levobupivacaine for interscalene brachial plexus blockade, Group III: $1: 400,000$ epinephrine as an adjuvant to $10 \mathrm{ml}$ of $0.5 \%$ levobupivacaine for interscalene brachial plexus blockade. 
procedure, the VNRS was notably lower than adding normal saline solution or $1: 400,000$ epinephrine up to 48 hours postsurgery, and it showed excellent extension of the pain control period without complications or side effects.

Arthroscopic shoulder surgery is known to cause severe postoperative pain similar to gastrectomy or thoracotomy $[7,18]$. ISBPB is conducted with local or general anesthetic for arthroscopic shoulder surgery and is not only an anesthetic method that allows easier blood pressure control during surgery, but also allows easier postoperative pain control. Thus, this method is used frequently because it reduces the need for opioids or analgesics, which in turn reduces nausea, vomiting and hypoxia [6-8,19,20]. Singelyn et al. [20] reported that ISBPB exhibited more effective analgesic effect during the first 24 hours than suprascapular nerve block or subacromial/intraarticular injection. Single-shot ISBPB provides excellent pain control effect for arthroscopic shoulder surgery compared to other methods, but the limitation is that the duration of pain control period is short. To counteract this, various medications are added and effective pain control is achieved [9-11,21]. Kim et al. [6] reported excellent pain control effects up to 8 hours post-surgery using $0.25 \%$ and $0.5 \%$ levobupivacaine $10 \mathrm{ml}$ in single-shot ISBPB under ultrasound guidance. In our study, ISBPB was conducted within the sheath of the interscalene brachial plexus using $10 \mathrm{ml}$ of levobupivacaine, and the inplane approach method was used to insert the needle. Direct damage to nerves and surrounding tissue from needle insertion was prevented by checking ultrasound images during insertion. Appropriate spread of LAs within the interscalene brachial plexus sheath was ascertained during administration, and the location of the needle tip was adjusted when needed. This allowed LAs injection into the appropriate areas for sufficient perfusion through the nerve trunk and roots so successful nerve block was properly achieved in all patients without complications and pain control effect of less than 1 VNRS up to 6 hours post-surgery was observed. These results are similar to those of previous studies.

Using $1: 400,000$ epinephrine as an adjuvant to levobupivacaine $10 \mathrm{ml}$, Group III was not statistically different to Group I, which used normal saline as an adjuvant, in VNRS comparison, over time. Existing research reporting positive results [22,23] had used relatively large dosages of bupivacaine or ropivacaine injected into the brachial plexus sheath between the ASM and MSM, and the small amount of epinephrine used to constrict the surrounding blood vessels to delay local anesthesia absorption, which led to prolonged pain control period. In our study, however, epinephrine did not result in a prolonged pain control period. The first reason may be the pharmacological difference caused by levobuvacaine, which is a $S(-)$ isomer of bupivacaine and is known for safer applications and lower possibility of adverse cardiovascular effects or neurotoxicity. The second reason may be that epinephrine could not function as a vasoconstrictor because local anesthesia was used in such small amounts to the cervical nerve roots or nerve trunks located within the space of the sheath, and injection was limited within the sheath.

In our study, when ISBPB was conducted with $5 \mathrm{mg}$ of dexamethasone as an adjuvant to levobupivacaine, a notable pain control extension effect could be observed up to 48 hours post-surgery. Existing studies of the pain control effect of dexamethasone in local anesthesia reported that the pain control period was significantly prolonged in IV regional anesthesia or axillary BPB using lidocaine, and supraclavicular BPB conducted with epinephrine as an adjuvant to bupivacaine $[15,16,24]$. However, these results could not completely exclude the systemic effect of corticosteroids. Moreover, epinephrine and/or clonidine were used together, so the sole effect mechanism of dexamethasone on LAs could not be fully explained. The analgesic mechanism of corticosteroids is not yet fully understood, and there is little known about the functional or structural influence of corticosteroids on normal peripheral nerve fibers $[25,26]$. However, it has been reported that the steroids induce a degree of vasoconstriction, which results in reducing LA absorption, and they attach to the intracellular receptor to modulate nuclear transcription [15]. Stan et al. [19] argued that the steroid suppresses the synthesis and secretion of various inflammatory mediators, which prolongs the period of analgesia up to 48 hours, and Attardi et al. [27] showed that dexamethasone act on glucocorticoid receptors, which increase the activity of inhibitory potassium channels on nociceptive C-fibers. This result concurs with ours, but more research on the influence of steroids on peripheral nerve fibers and its mechanisms is necessary.

The danger of using dexamethasone within the nerve sheath is still controversial. In animal experiments, repeated intrathecal injections of small dosages of bethamethasone and triamcinolone did not cause spinal toxicity, but repeated intrathecal injection of high dosages of betamethasone resulted in histological changes in the spinal cord $[13,14]$. In contrast, neurological abnormalities were not observed when repeated spinal injection of $8 \mathrm{mg}$ dexamethasone was applied to treat post-traumatic visual disturbance. Therefore, neural damage appears to be highly related to direct trauma by the needle. In addition, it is reported that single use of small amounts (less than $8 \mathrm{mg}$ ) of dexamethasone, or use within 24 hours, is safe for adults $[15,28,29]$. In our study, a smaller dose of $5 \mathrm{mg}$ of dexamethasone was injected between the $\mathrm{C} 5 / 6$ roots within the sheath, while checking the nerves and spread of local anesthesia through ultrasound images. This may be why the procedure was highly successful, since all nerve blocks were 
completely recovered within 24 hours without neural damage, and the excellent analgesic effect lasted up to $48 \mathrm{~h}$ post-surgery.

In conclusion, using low dosage $0.5 \%$ levobupivacaine $10 \mathrm{ml}$ in ultrasound-guided single shot ISBPB for patients undergoing arthroscopic shoulder surgery showed an excellent pain control effect of less than 1 point of VNRS up to 6 hours post-surgery. Furthermore, when $5 \mathrm{mg}$ dexamethasone was used as an adjuvant in the ISBPB, it showed excellent pain control period extension of low VNRS up to 48 hours post-surgery without specific complications when compared to adding the same volume of adjuvant normal saline or $1: 400,000$ epinephrine.

\section{References}

1. Winnie AP. Interscalene brachial plexus block. Anesth Analg 1970; 49: 455-66.

2. Rucci FS, Pippa P, Barbagli R, Doni L. How many interscalenic blocks are there? A comparison between the lateral and posterior approach. Eur J Anaesthesiol 1993; 10: 303-7.

3. Meier G, Bauereis C, Heinrich C. Interscalene brachial plexus catheter for anesthesia and postoperative pain therapy. Experience with a modified technique. Anaesthesist 1997; 46: 715-9.

4. Piangatelli C, De Angelis C, Pecora L, Recanatini F, Cerchiara P, Testasecca D. Levobupivacaine and ropivacaine in the infraclavicular brachial plexus block. Minerva Anestesiol 2006; 72: 217-21.

5. Cline E, Franz D, Polley RD, Maye J, Burkard J, Pellegrini J. Analgesia and effectiveness of levobupivacaine compared with ropivacaine in patients undergoing an axillary brachial plexus block. AANA J 2004; 72: 339-45.

6. Kim JJ, Kim CH, Kim YJ, Kim DY, Han JI. Analgesic effect of low-dose levobupivacaine for ultrasound-guided interscalene brachial plexus block for arthroscopic shoulder surgery. Korean J Anesthesiol 2009; 57:302-7.

7. Tuominen M, Pitkänen M, Rosenberg PH. Postoperative pain relief and bupivacaine plasma levels during continuous interscalene brachial plexus block. Acta Anaesthesiol Scand 1987; 31: 276-8.

8. Fredrickson MJ, Krishnan S, Chen CY. Postoperative analgesia for shoulder surgery: a critical appraisal and review of current techniques. Anaesthesia 2010; 65: 608-24.

9. Förster JG, Rosenberg PH. Clinically useful adjuvants in regional anaesthesia. Curr Opin Anaesthesiol 2003; 16: 477-86.

10. McCartney CJ, Duggan E, Apatu E. Should we add clonidine to local anesthetic for peripheral nerve blockade? A qualitative systematic review of the literature. Reg Anesth Pain Med 2007; 32: 330-8.

11. Glasser RS, Knego RS, Delashaw JB, Fessler RG. The perioperative use of corticosteroids and bupivacaine in the management of lumbar disc disease. J Neurosurg 1993; 78: 383-7.

12. Kopacz DJ, Lacouture PG, Wu D, Nandy P, Swanton R, Landau C. The dose response and effects of dexamethasone on bupivacaine microcapsules for intercostal blockade (T9 to T11) in healthy volunteers. Anesth Analg 2003; 96: 576-82.

13. Abram SE, Marsala M, Yaksh TL. Analgesic and neurotoxic effects of intrathecal corticosteroids in rats. Anesthesiology 1994; 81: 1198-
205.

14. Latham JM, Fraser RD, Moore RJ, Blumbergs PC, Bogduk N. The pathologic effects of intrathecal betamethasone. Spine (Phila Pa 1976) 1997 ; 22 : 1558-62.

15. Movafegh A, Razazian M, Hajimaohamadi F, Meysamie A. Dexamethasone added to lidocaine prolongs axillary brachial plexus blockade. Anesth Analg 2006; 102: 263-7.

16. Bigat Z, Boztug N, Hadimioglu N, Cete N, Coskunfirat N, Ertok E. Does dexamethasone improve the quality of intravenous regional anesthesia and analgesia? A randomized, controlled clinical study. Anesth Analg 2006; 102: 605-9.

17. Tan PH, Liu K, Peng CH, Yang LC, Lin CR, Lu CY. The effect of dexamethasone on postoperative pain and emesis after intrathecal neostigmine. Anesth Analg 2001; 92: 228-32.

18. Wang YL, Tan PP, Yang CH, Tsai SC, Chung HS. Epidural dexamethasone reduces the incidence of backache after lumbar epidural anesthesia. Anesth Analg 1997; 84: 376-8.

19. Stan T, Goodman EJ, Bravo-Fernandez C, Holbrook CR. Adding methylprednisolone to local anesthetic increases the duration of axillary block. Reg Anesth Pain Med 2004; 29: 380-1.

20. Singelyn FJ, Lhotel L, Fabre B. Pain relief after arthroscopic shoulder surgery: a comparison of intraarticular analgesia, suprascapular nerve block, and interscalene brachial plexus block. Anesth Analg 2004; 99: 589-92.

21. Choyce A, Peng P. A systematic review of adjuncts for intravenous regional anesthesia for surgical procedures. Can J Anaesth 2002; 49 32-45.

22. Singelyn FJ, Dangoisse M, Bartholomée S, Gouverneur JM. Adding clonidine to mepivacaine prolongs the duration of anesthesia and analgesia after axillary brachial plexus block. Reg Anesth 1992; 17: 148-50.

23. Culebras X, Van Gessel E, Hoffmeyer P, Gamulin Z. Clonidine combined with a long acting local anesthetic does not prolong postoperative analgesia after brachial plexus block but does induce hemodynamic changes. Anesth Analg 2001; 92: 199-204.

24. Shrestha BR, Maharjan SK, Shrestha S, Gautam B, Thapa C, Thapa $\mathrm{PB}$, et al. Comparative study between tramadol and dexamethasone as an admixture to bupivacaine in supraclavicular brachial plexus block. JNMA J Nepal Med Assoc 2007; 46: 158-64.

25. Johansson A, Hao J, Sjölund B. Local corticosteroid application blocks transmission in normal nociceptive C-fibres. Acta Anaesthesiol Scand 1990; 34: 335-8.

26. Haimovic IC, Beresford HR. Dexamethasone is not superior to placebo for treating lumbosacral radicular pain. Neurology 1986; 36: 1593-4.

27. Attardi B, Takimoto K, Gealy R, Severns C, Levitan ES. Glucocorticoid induced up-regulation of a pituitary $\mathrm{K}+$ channel mRNA in vitro and in vivo. Receptors Channels 1993; 1: 287-93.

28. Vieira PA, Pulai I, Tsao GC, Manikantan P, Keller B, Connelly NR. Dexamethasone with bupivacaine increases duration of analgesia in ultrasound-guided interscalene brachial plexus blockade. Eur J Anaesthesiol 2010; 27: 285-8.

29. Frederick HA, Carter PR, Littler JW. Injection injuries to the median and ulnar nerves at the wrist. J Hand Surg Am 1992; 17: 645-7. 